\title{
Natural Capital: Illuminating the True Value of Nature's Services through Community-Engaged, Site-Specific Creative Production and Exhibition
}

\author{
Sarah Van Borek, MFA
}

\begin{abstract}
The Natural Capital Project is an interactive community mapping and storytelling project designed to promote the nonmarket value of nature's essential ecosystem services in the Lower Mainland region of British Columbia, Canada, and shed new light on the importance of fragile coastal ecosystems in people's lives. The project was developed through a two-semester cross-disciplinary studio-based community projects course in the Faculty of Culture + Community at one of Canada's leading postsecondary art institutions, the Emily Carr University of Art + Design (Vancouver), in partnership with one of Canada's leading environmental organizations, the David Suzuki Foundation (DSF).

Through a dynamic and collaborative approach to documentary practices, postsecondary art students across a variety of levels and disciplines created a series of digital narratives for an app in development by DSF designed to bring to life their report on aquatic ecosystems in British Columbia's Lower Mainland. The study estimates that the region's wetlands, beaches, and coastal areas provide at least $\$ 30$ to $\$ 60$ billion in economic benefits to residents every year.

The course culminated in a museum exhibit at the Gulf of Georgia Cannery (GoGC) in Steveston, British Columbia, offering students the opportunity to see the effects of their work in a public space and feel like their input could have an impact on the environment and in changing hearts and minds.
\end{abstract}

\section{Introduction}

What is nature worth? To you personally? To your neighborhood? To your citiy? To your country? To our global community?

There are a variety of ways we can value nature. I think of the value of nature in terms of the priceless memories I have of chance encounters with creatures in the wild. Growing up, I spent my summers on the west coast of Vancouver Island where I would be only too delighted to have a day of fishing spoiled by a parade of orcas going by. As the prominent Canadian environmental advocacy organization, the David Suzuki Foundation's Director General, Ontario and Northern Canada, Faisal Moola says: "There is no right way to value nature, but there is a wrong way, and that is to give it a zero value."

Traditionally, nature has been valued as a commodity: How much is this area of land worth if we want to clear it for urban development? How much are these trees worth if we want to use them for building materials? This system of valuing nature is extremely problematic and a key contributor to our environmental and economic crises. When decision makers sit down at the table to make tough choices about whether to preserve a natural area or transform it into urban infrastructure, they're doing a cost-benefit analysis, but they have a giant blind spot because there's an enormous value of nature that's missing from the equation: nature's services.

The scientific community has come up with a new system for valuing naturelooking at its ecosystem services in monetary values. What is meant by ecosystem services? These are the services nature provides to us ... things like filtering water, storing carbon, or as illustrated

Emily Carr University of Art + Design, Faculty of Culture + Community, Vancouver, British Columbia, Canada. 
in Figure 1, how bird droppings play an important role in seed dispersal. These services are free, often not accounted for, and yet absolutely critical to human well being. The process of valuing these services in monetary terms is fairly complex, but can roughly be understood as what it would cost us if we had to replicate them through human-made efforts.

The David Suzuki Foundation (DSF) is a Canadian, nonprofit that acts as a catalyst for social change. They work with
Mainland region of the province of British Columbia. In a briefing note, DSF's environmental economist, Michelle Mollnar, and Simon Fraser University economist Nancy Olewiler defined Natural Capital as: "the term given to our planet's renewable and non-renewable natural resources - land, atmosphere, water, and the many diverse ecosystems that support life. Natural capital provides economically valuable goods and services ('ecosystem services'). Some of these have well-defined markets; these

\section{Let a Bird Poop}

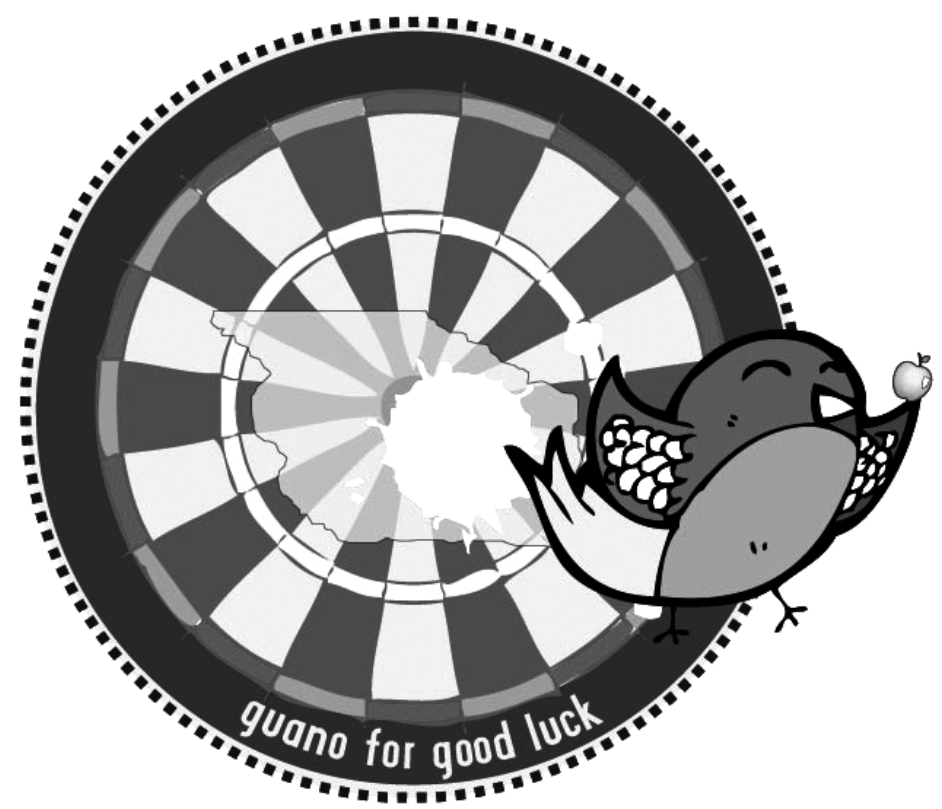

The value of seed dispersal in BC Lower Mainland is worth THOUSANDS each year

BIRDS NEED TO EAT \& POOP FOR PLANT SEED TO DISPERSE. AS BIRDS INGEST FRUIT PULP. THE SEEDS INSIDE THE PULP PROGRESS THROUGH THEIR DIGESTIVE SYSTEMS \& THEN PASSED THROUGH DROPPINGS WITHA SMALL DOSE OF FERTILIZER. THROUGH THEIR POOP. BIRDS HELP ECOSYSTEM FLOURISH.

Figure 1. Let a Bird Poop - Design by Bianca Channer, OCAD University

government, businesses, and individuals to protect the health of communities and the environment through science-based research, education, advocacy, and policy work. Over the last few years, DSF has done extensive research on natural capital in the southwestern region of the province of Ontario and the Lower include minerals, oil, gas, commercial forests and fisheries. Others are not traded in markets but sustain life; these include soil microorganisms, our atmosphere, and the quality of the water use $\mathrm{e}^{1}$ for consumption or production." ${ }^{2-4}$ DSF has released numerous reports outlining the results of this research.
In 2012, DSF designed a Natural Capital Map App to make this data more accessible to the public. The app user chooses four points to circumscribe a land mass on the map and the app then does a tally and pulls up a report outlining the various ecosystem services in that region, along with their dollar value and the total monetary value of all these services in that region. The app can be accessed for free online at the DSF website: http:// naturalcapital.davidsuzuki.org/.

While the Natural Capital Map App provides one tool to help inform the public, DSF wanted to ramp up its public education strategy. When I first proposed to DSF that I wanted to develop a course at ECUAD that would support their natural capital work while enabling students to apply their art skills to sustainability initiaves, DSF quickly identified a need for personal stories from community members to help make the research more relevant to people in their day-today lives. DSF also wanted to fill a gap in their ecosystem services valuing system, an outgrowth of not being able to add a monetary value to certain cultural services that nature provides. Cultural services refers to cultural, spiritual, cognitive, and health benefits, the meaning and importance of which is relative to each person's experience, making it difficult to easily monetize.

This is where the creative arts stepped in. Building on the power of digital storytelling to document human experience and inspire social change, postsecondary art students created videos of stories told by diverse Vancouver residents speaking about the cultural benefits they receive from specific natural areas in Vancouver. These videos* have been integrated into DSF's Natural Capital Map App to help expland DSF's public outreach to nontraditional audiences, an underlying goal of which is to inspire Vancouver residents to pressure government to implement policies that help to protect and preserve these precious ecosystems.

This creative arts approach to sustainability also builds on a mobilizing strat-

\footnotetext{
* All eight videos about beaches from the spring 2013 semester have been integrated into the Natural Capital Map App. The 15 videos about wetlands from the fall 2012 semester currently sit on a separate website (www.davidsuzuki.org/bcwetlands) developed by Emily Carr students in collaboration with DSF's digital strategies team. This was the initial platform for the videos to be shared publicly during a time when the Nat Cap Map App was still under development. The Nat Cap Map App was created as something that would be capable of continuous upgrades to accommodate new valuations, science, and outreach materials. This includes the work of Emily Carr students.
} 
egy called The Ambassador Model that DSF has applied to various other environmental campaigns. The Ambassador Model is based on the principle that people are most likely to change their behavior when they are inspired to do so by someone they trust who has made the change first. Recruiting ambassadors (people who are known and respected by others) from diverse communities to share their personal testimonies about the services they receive from nature taps into the networks of each ambassador, motivating others to shift the way they see, think, and act with regards to this issue.

\section{Materials and Methods}

The Natural Capital Project was offered as an interdisciplinary, studio-based Community Projects course for the first time at the Emily Carr University of Art + Design (ECUAD) in the fall semester of 2012. This course was part of a minor in Social Practice and Community Engagement (SPACE) in ECUAD's Faculty of Culture + Community and was made possible through a partnership with DSF.

In fall 2012, the students' digital narrative videos featured five wetlands in Vancouver that were identified by DSF as senstive ecosystems. What are wetlands and why did the Natural Capital Project involve a focus on them? While their form varies (swamps, bogs, marshes, etc), wetlands have been historically undervalued, often seen as useless or wasted land that would be more valuable if converted to other uses (e.g., urban infrastructure). As a result, many have been destroyed. Around 70 percent of the wetlands originally in Canada have already disappeared. ${ }^{5}$ Those remaining represent one-fourth of the world's wetlands. ${ }^{6}$

Despite their varied forms, wetlands can be identified by their essential ecosystem services. Figure 2 shows that wetlands are like giant sponges that provide important services such as storing water, filtering toxins, and transforming nutrients. As a result, wetlands score very high in natural capital values (in fact the highest out of land cover types in DSF's

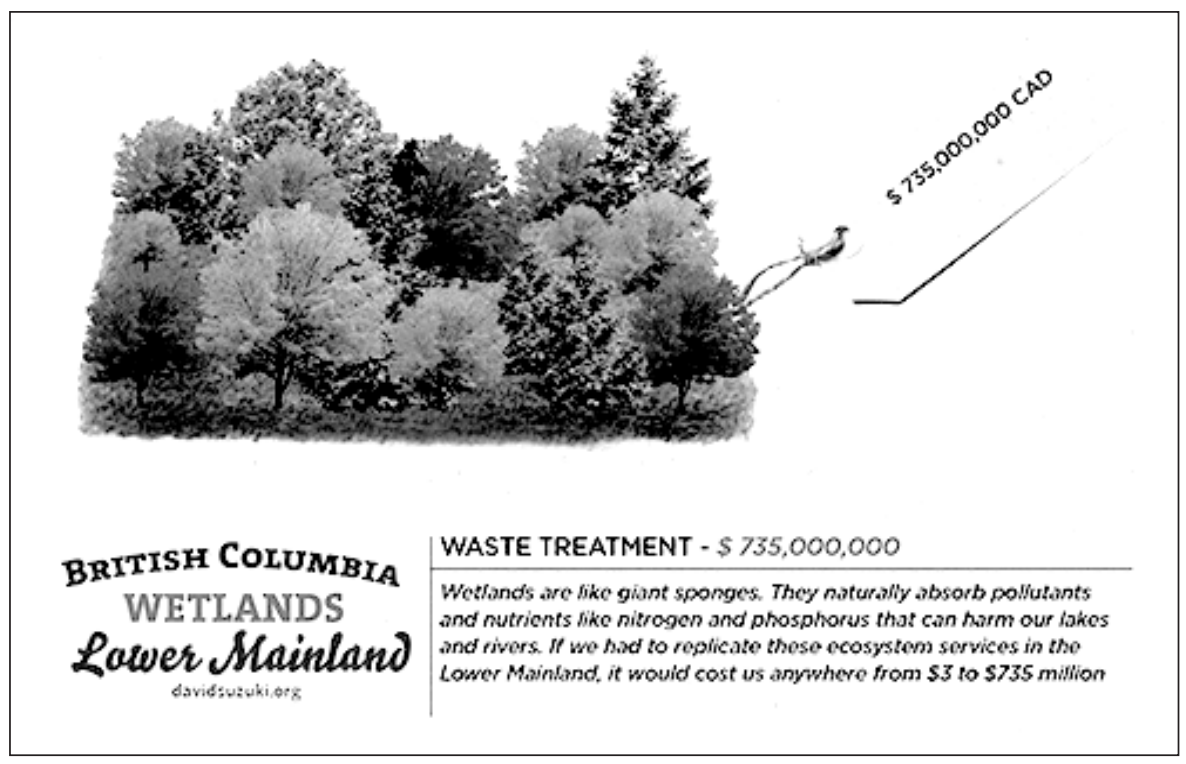

Figure 2. Waste Treatment - Design by Lauren Livingston, OCAD University

most recent report-up to $\$ 4.645$ billion annually in the B.C. Lower Mainland). ${ }^{4}$ So, wetlands are historically undervalued, and yet absolutely critical to human well-being.

In fall 2012, the project included various creative collaborators and elements. One key collaboration consisted of four second-year design students from OCAD University in Toronto, led by OCADU instructor Linda Montgomery, who worked directly with DSF's Toronto office. This group, known as the ECOCAP (Ecological System Capital) Team, built on their natural capital data visualization work initiated by Montgomery earlier in 2012, pertaining to the Rouge National Urban Park in Ontario. This collaboration contributed 16 original posters (adaptations of Rouge Park posters customized for BC Wetlands and BC Lower Mainland ecosystems) illustrating the meaning and definition of ecosystem services (see Figure 1 and Figure 2 ), introduction and acknowledgement signage for the exhibit, and design concepts for the opening title sequences of the videos.

Two additional ECUAD instructors collaborated on the project by inviting their students to contribute creative content. A series of experimental site-specific videos exploring the characteristics of each of the featured wetlands were cre- ated by Julie Andreyev's second-year students in the Video for Social Media program in ECUAD's Faculty of Interactive and Social Media Arts (ISMA). Since the Natural Capital Map App for the Lower Mainland was still in development at the time of the fall 2012 course, an interim web platform to host the project's video content was designed by Jim Andrews's three second-year students in the Web Essentials course in ECUAD's ISMA program.

In spring 2013, I was invited to teach The Natural Capital Project/course for a second semester, this time with a focus on eight Vancouver beaches. This enabled eight ECUAD students in the Community Projects program to each create a video that featured a story about a beach in Vancouver and a range of essential and lesser-known ecosystem services the beach provides. Ecosystem services highlighted in the videos range from educational and spiritual to flood control, habitat, and food provision, to name a few. Each video focuses on a different beach.

Beaches rank high in natural capital value, second to wetlands according to DSF's latest report. ${ }^{4}$ While Vancouver is renowned for its many beaches, most residents (and visitors) perceive them mainly as sites for human recreation. ECUAD students' creative work pro- 


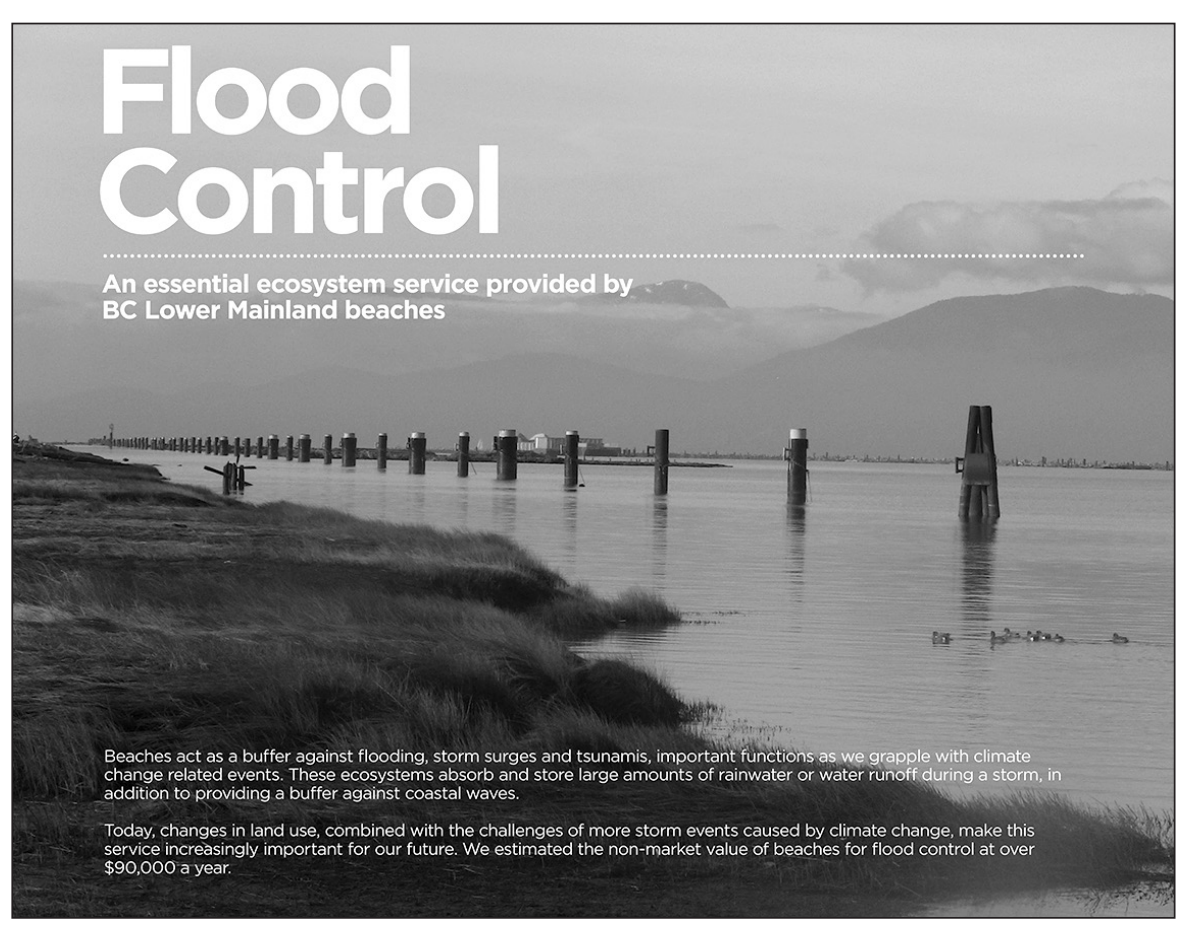

Figure 3. Flood Control - Design by Anton Mwewa and Lauren Livingston, OCAD University; Photo of lona Beach by Omar Linares, ECUAD

duced as part of the spring 2013 Natural Capital Project aims to raise awareness of the human and nonhuman benefits of these lesser-known ecosystem services.

In both fall and spring semesters of the academic year 2012-2013, to expand on the public outreach of our work, the Natural Capital course I taught culminated in an exhibition of students' work at the Gulf of Georgia Cannery (GoGC) in Steveston, British Columbia (BC). GoGC is a national historic site and museum dedicated to the fishing history of British Columbia with contemporary exhibits focused on sustainability issues related to coastal communities in the province. GoGC is an important cultural institution in the region, with an estimated 50,000 visitors annually. GoGC was an official partner of the 2012-2013 Natural Capital Project.

In addition to repurposing their videos for the exhibit, students were involved in creating interpretive signage for the exhibit, and the spring semester students also created panoramic photographs and audio clips of walks on the beaches, which were incorporated into a virtual beach video installation. In December 2012 ECUAD students also facilitated a workshop at GoGC with Westwind Elementary School in Richmond, BC, with students in grades 5 and 6 , taking them through the exhibit and having them creatively interpret their own experiences with nature and their understanding of the value of wetlands in Vancouver.

\section{Results}

\section{Museum Exhibit Provides New Audience and Motivation}

By having students' work culminate in a museum exhibit at the end of the semester, the students' messages automatically reached a broad audience, one distinctly different from those who may have encountered the work through the Natural Capital Map App, DSF's YouTube channel, or social media posts. The demographics of the museum's visitors range from local residents and school groups to international tourists, social clubs, and more. This particular museum also offers a space for non-museum community activities (e.g., a local farmers' market, holiday events, etc.), which bring nontraditional audiences into the museum space, automatically face-toface with the exhibits.

The museum context calls for a different style of presentation for the work produced through the Natural Capital Project, and has so far inspired interactive stations, dynamic interpretive signs, and artists' statements that bring added depth and meaning to the work. By locating the work in a physical place,

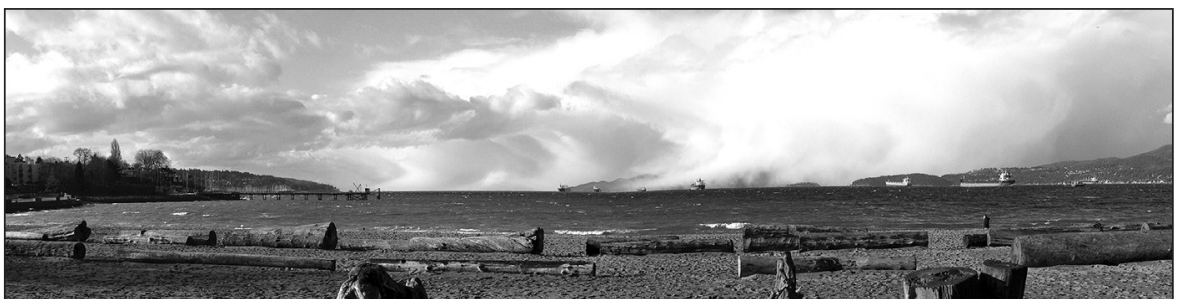

Figure 4. Kits Beach Panorama - Sigrid Lei Gong, ECUAD

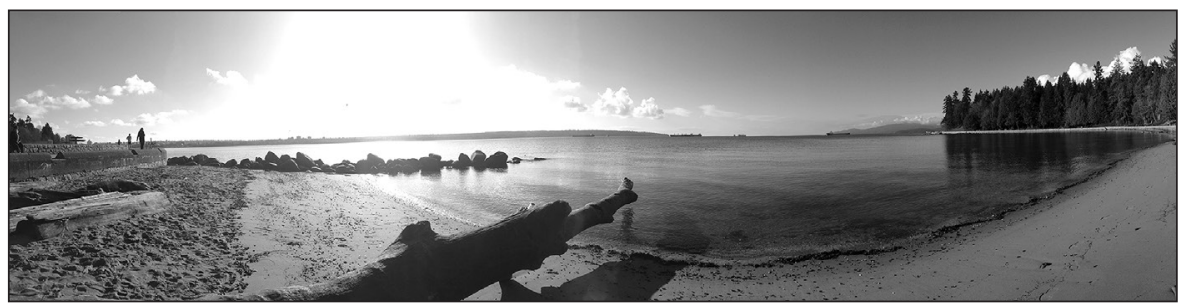

Figure 5. Third Beach Panorama - Fiona Samson, ECUAD

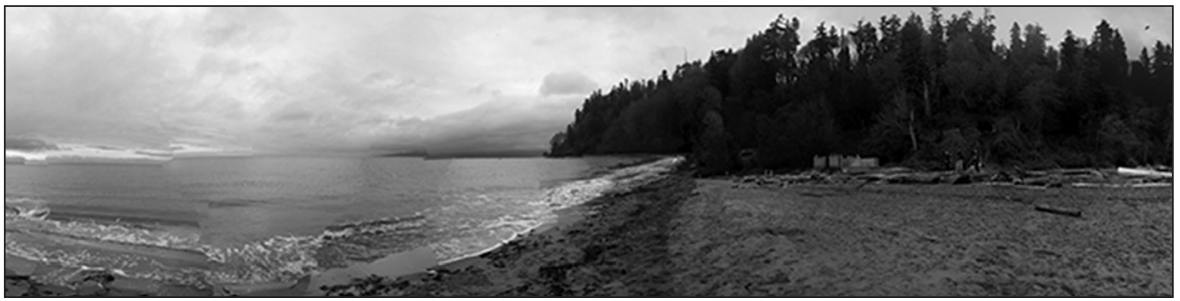

Figure 6. Wreck Beach Panorama - Jen Treptow, ECUAD 
museum visitors are provided with an opportunity to experience the work in a way that online users, more accustomed to finding it when searching for related content or finding it by chance, cannot. At the same time, encountering the work in the museum space may then inspire visitors to later view the work online, where they can then learn about more opportunities to get directly involved in promoting social change, e.g., signing a Wetlands Declaration ${ }^{7}$ or other petitions, etc.

Having a museum exhibit and launch at the end of the semester certainly adds further motivation to students' commitment and work ethic. It raises the stakes of their responsibility. Not only do they have a project due for a grade and then a deliverable for a highly reputable nonprofit (DSF), but they also have a professional exhibit in a public museum (GoGC) that will be on display for a considerable time (three to four months). It also gives students an ambitious but rewarding goal to work toward, and the exhibit launch serves as an essential rite of passage for students to celebrate their own learning, talents, and efforts while receiving well-deserved recognition. This experience will hopefully continue to inspire students to remain community-engaged artists well beyond their involvement in the course.

\section{An Increased Public Profile for Natural Capital}

As this project moves through its pilot phase and begins to take root for longer-term expansion, it is beginning to generate interest from the academic community as well as the sustainability and arts sectors. This progression further promotes the concept of natural capital to nontraditional audiences, giving the students a broader audience for their work and consequently an increased sense of having made an impact. This takeaway, in turn, promotes the value of this kind of collaborative, interdisciplinary course and increases the likelihood that the project will continue to evolve. The course as a more permanent part of the curriculum may also help to inspire other institutions and organizations to consider applying this model.

\section{Solidifying Partnerships}

One very important result of this project is the partnerships that are solidifying

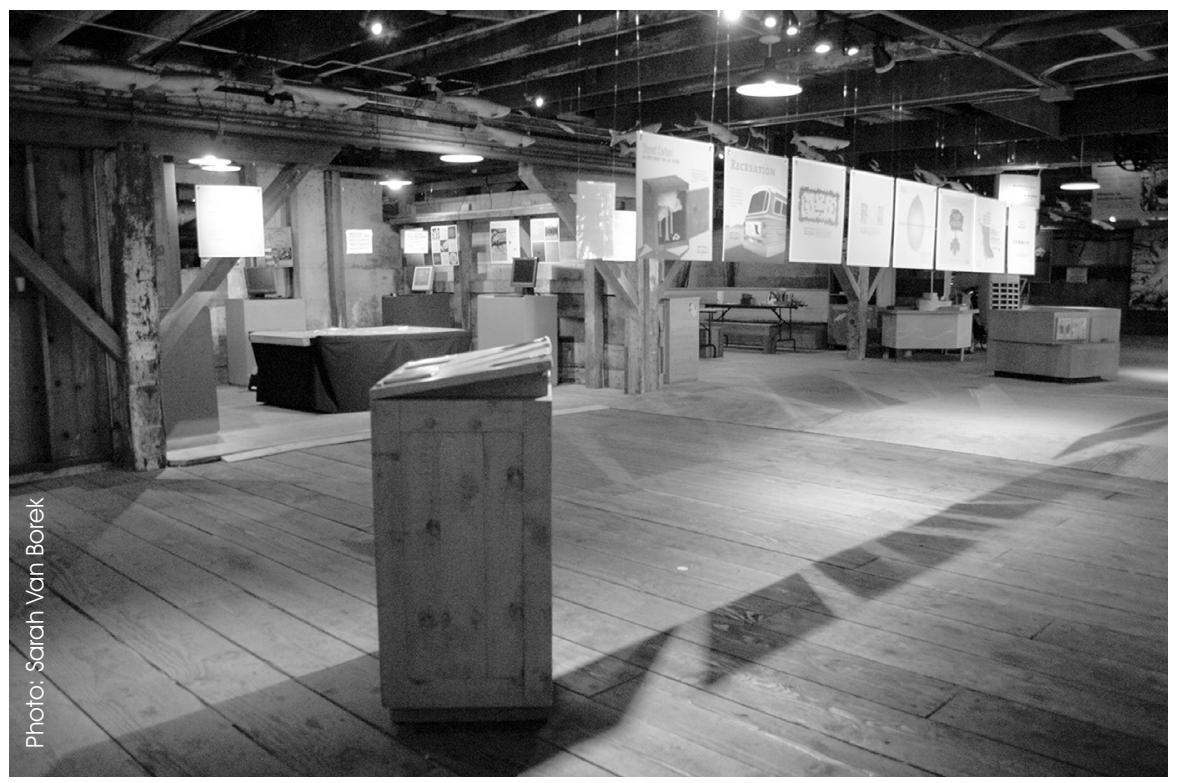

Figure 7. Natural Capital - Fall 2012 exhibit at the Gulf of Georgia Cannery

between DSF, GoGC, and ECUAD. With all stakeholders recognizing the value in this partnership come opportunities for continuing to grow the potential of this synergy:

"We leapt at the opportunity to work with the David Suzuki Foundation. Natural capital is an ideal example of a partnership that speaks to Emily Carr's values of community engagement and social responsibility," says Susan Stewart, dean of the Faculty of Culture + Community at Emily Carr. "This unique project will both educate and inform the public about valuing and protecting our natural capital in Vancouver and beyond."

"Bringing an artistic lens to this natural capital work brings it to life for people," explains Michelle Molnar, an environmental economist with the David Suzuki Foundation. "We're excited about the collaboration between art and economics and the passion it can create in people to act to protect their own ecosystems."

"At the Cannery, we are always looking for different ways to reach our visitors," remarks Karen Lee, public programs manager at GoGC. "I feel that our partnership with ECU/DSF enables us to highlight environmental issues in innovative ways. The students' work personalizes complex issues and makes them accessible to visitors. The Cannery has been trying to integrate more content about current issues related to fishing and waterways, so the project is a great fit."

\section{Responsible Resource Management and "Compassionate Action Muscle"}

I have many students who have said that Natural Capital is their favorite course at ECUAD because the assignments and projects have real-world implications, which offer an added sense of meaning and purpose to their work. I see this course as a part of responsible resource management. There are all these young people with artistic talents and creative energy who have signed up for an arts degree program. They aim to learn technical skills and develop their creative muscle while uncovering their unique artistic voice and place in the world. This process involves their time, energy, and financial resources for materials.

There are many creative arts programs that reinforce the practice of art-making solely as research and education. In this type of program, projects and assignments are for the sole purpose of learning a technique or getting a grade and students might even ask, Do I have to keep this after the critique? A course like Natural Capital endeavours to bring added meaning and function to the students' learning experience, time, energy, materials, and resources. At the same time, it enables these students to develop both their creative muscle and what I like to think of as their "compassionate action muscle"-awakening in them a sense of purpose and motivation, and evidence that they can do something to make a difference. This is something that can be seen as added value for all involved. 


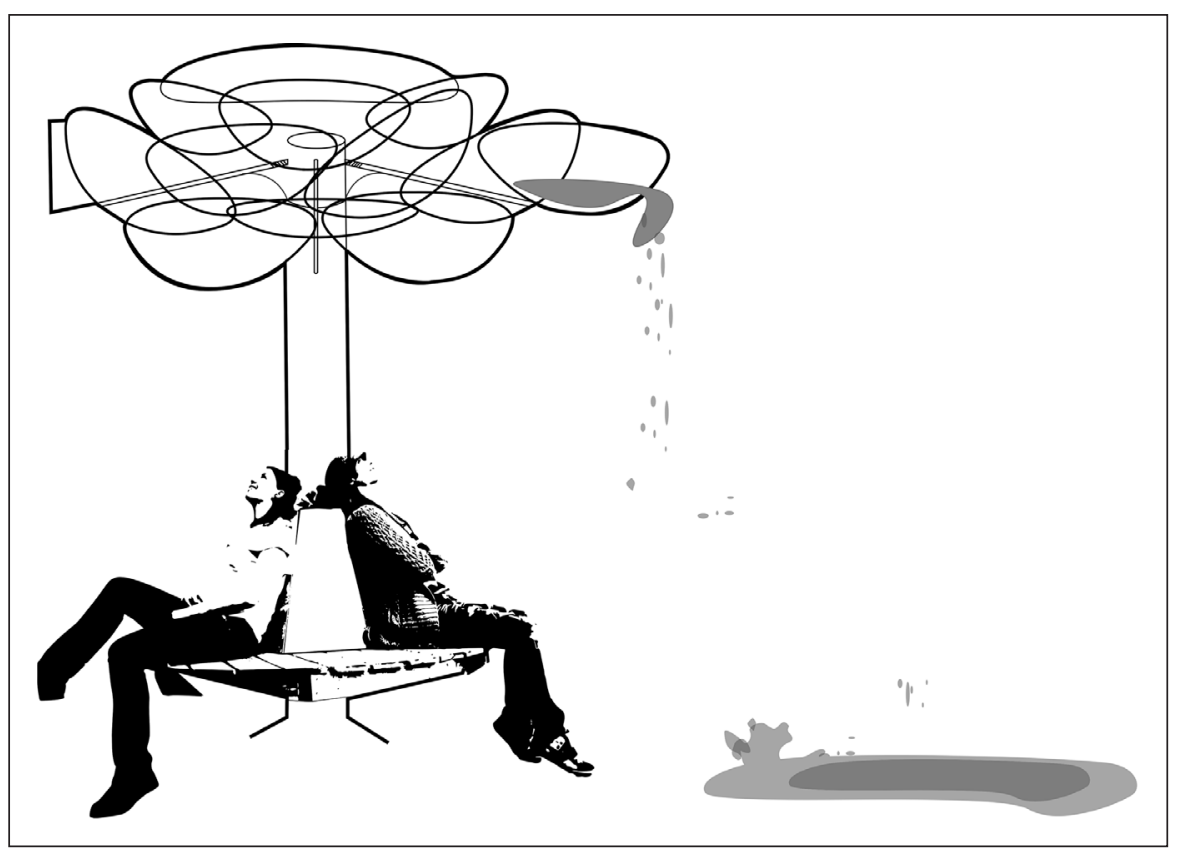

Figure 8. Heather Mitchell's Rain Bench

For me, the most significant outcome of this project was the way it activated the students. The fall 2012 semester involved 15 students, two of whom in the final year of their degree decided to focus their major/graduate project on continuing this work by building on their relationships with DSF and local wetlands. Heather Mitchell, an industrial design major, created a Rain Bench. In the fall 2013, as part of her student group work of producing videos, Mitchell spent considerable time building relationship with and interviewing three community members about the Jericho Park wetland. Mitchell recounted how the course inspired her Rain Bench: "After closely looking at each interviewee, I realized that all park visitors had one common shared interest, which was not an emotional benefit. This was the typical park bench. The artistic and aesthetic uniqueness in this bench lies in its ability to provide a pleasing and relaxing sound created from its roof system when it rains. How nice for an individual to smile and think, Since it is raining, I am going to the park to sit under the rain canopy so that I may relax and enjoy the sound of the raindrops being funneled onto the canvas water catchers." DSF made a significant financial contribution to support the production of Mitchell's Rain Bench and the bench was accepted by the city of Vancouver to be installed in a city park.
Maria Belen Scaglia, an interactive design major, also established a relationship with a related nonprofit called the BC Wildlife Federation (BCWF), and through this project, she worked with BCWF and DSF to design a cutting-edge Wetland Mapping App. For both students, these projects demonstrated their ability to build on existing relationships, to expand their own awareness of issues, to take initiative, and to apply their own ideas and artistic skills to something that could have a positive impact in the world

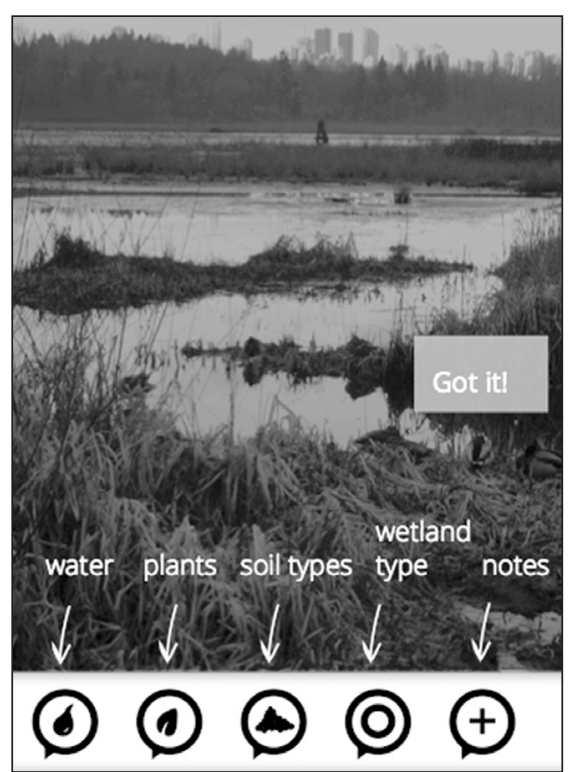

Figure 9. Maria Belen Scaglia's Wetland Mapping App around them. Maria Belen said of the course, "I found what I want to do."

To have been able to create the conditions in which an energetic, talented, and enthusiastic young person could find passion and purpose in her life and the world ... this is the true value of this work.

\section{Creative Arts Ramp Up Potential for Social Media Campaigning}

Today's marketing, whether it involves commercial or social campaigns, takes place largely through social media. The impact of cross-posting and re-tweeting is well understood. DSF is doing cutting-edge research in a variety of areas related to the environment and policy change, notably around natural capital. However, this research through the more typical science-based methods of information-sharing (i.e., reports, surveys, tables, etc.) does not go viral in the same way as quirky YouTube video sensations like "Double Rainbow" and "David Goes to the Dentist." What is more likely to capture the imagination of the masses and inspire viral social networking is communication that takes advantage of images that awaken our hearts and minds. And when these images can be combined with powerful testimonies from ambassadors in our communities, people who we know and trust, the impact can be that much greater.

The results of this project to date emphasize the value of not only wetlands, beaches, and ecosystem services but also the value of having postsecondary art students from Emily Carr collaborate with the David Suzuki Foundation. While a figure like $\$ 30-\$ 60$ billion annually for aquatic ecosystem services in BC's Lower Mainland may grab peoples' attention, perhaps what will move people to get involved in preserving and protecting our precious wetlands and beaches is hearing stories from people in our community through engaging and meaningful videos created by talented art students.

Whether it's the shocking monetary figures, the heart-warming stories, or a combination of both, I hope this work will inspire you to ponder one question: What is nature worth...to you? 


\section{Acknowledgments}

The Natural Capital Project required input from a variety of sources. We greatly appreciate the contribution and support of the following: Emily Carr University of Art + Design (Susan Stewart, Roxanne Toronto, Jim Andrews, Julie Andreyev), ECUAD Students (Roshanak Amini, Julian Araneta, Ashleigh Begg, Samantha Borje, Vicky Ting-Wei T. Chu, Joni Danielson, Stephan Garneau, Sigrid Lei Gong, Micaelee Hanson, Zoe Hardisty, Kaitlyn Hendry, Larry Ho, Siobhan Hyde, Emily Kao, Kiran Lakhani, Ya Feng Janice Lan, Omar Linares, Jessica MacDaniel, Georgia Mackenzie-MacPherson, Heather Mitchell, Cole Pauls, Fiona Samson, Maria Belen Scaglia, Leigh Selden, Melissa Soleski, Shannon Stewart, Jen Treptow, Anaïsa Visser, Caelan Warnock, Alison Westdorp, Arielle White, Madeleine Wynne, Alexandria Tsang), OCAD University (Bianca Channer, Alex Gebhardt, Lauren Livingston, Linda Montgomery, Anton Mwewa), David Suzuki Foundation (Theresa Beer, Chris DePaul, Heidi Hudson, Sophika Kostyniuk, Michelle Molnar, Faisal Moola, Michiah Prull, Jay Ritchlin, Jode Roberts), Gulf of Georgia Cannery (Christina Froschauer, Karen
Lee), Jeremy Therrien, Free Geek and our invaluable community participants.

\section{Author Disclosure Statement}

No competing financial interests exist.

\section{References}

1. Understanding Ecosystems: How Businesses Can Manage Risks and Opportunities from "Natural Capital" by Michelle Molnar and Nancy Olewiler, 2012. http://www.nbs.net/knowledge/ understanding-ecosystems-how-businesses-can-manage-risks-and-opportunities-from-natural-capital/ (last accessed 09/04/2013).

2. David Suzuki Foundation. Ontario's Wealth, Canada's Future: Appreciating the Value of the Greenbelt's Eco-Services, 2008. http://www.davidsuzuki.org/publications/reports/2008/ontarios-wealthcanadas-future-appreciating-the-value-of-the-greenbelts-eco-serv/ (last accessed 08/22/2013).

3.Natural Capital in BC's Lower Mainland: Valuing the Benefits from Nature, 2010. http://www.davidsuzuki.org/publications/reports/2010/natural-capital- in-bcs-lower-mainland/ (last accessed 08/22/2013).

4.Nearshore Natural Capital Valuation, 2012. http://www.davidsuzuki.org/ publications/reports/2012/nearshorenatural-capital-valuation/ (last accessed 08/22/2013).

5. Ducks Unlimited. Why Should I Care? http://www.ducks.ca/learn-aboutwetlands/why-i-care/ (last accessed 08/26/2013).

6. http://www.biodivcanada.ca/default. asp?lang=En\&n=F07D520A-1 (last accessed 08/27/2013).

7. David Suzuki Foundation, World Wildlife Fund, B.C. Wildlife Federation, South Coast Conservation Program and Ducks Unlimited Canada. http://www. davidsuzuki.org/publications/downloads/wetlandsdeclaration.pdf (last accessed 08/29/2013).

Address correspondence to:

Sarah Van Borek, MFA

Emily Carr University of Art + Design

1399 Johnston Street

Vancouver, British Columbia

Canada V6H 3R9

E-mail: svanborek@ecuad.ca 